\title{
Sources of Resistance to Pepino mosaic virus in Tomato Accessions
}

Kai-Shu Ling, United States Department of Agriculture-Agricultural Research Service, U.S. Vegetable Laboratory, Charleston, SC 29414; and John W. Scott, University of Florida, Gulf Coast Research \& Education Center, Wimauma 33598

\begin{abstract}
Ling, K.-S., and Scott, J. W. 2007. Sources of resistance to Pepino mosaic virus in tomato accessions. Plant Dis. 91:749-753.

Pepino mosaic virus (PepMV) is an emerging disease on greenhouse tomato. This highly contagious disease is difficult to control. The best disease management strategy is likely through the use of disease resistance. A major tomato germplasm core collection was evaluated for its resistance against PepMV. These accessions included 23 Solanum lycopersicum, 8 S. pimpinellifolium, $33 \mathrm{~S}$. peruvianum, $18 \mathrm{~S}$. chilense, and $27 \mathrm{~S}$. habrochaites. The results showed that all plants in the accessions corresponding to $S$. lycopersicum and $S$. pimpinellifolium were susceptible to PepMV-US infection. On the other hand, two accessions of $S$. peruvianum (LA107 and LA1305) and S. chilense (LA1971 and LA2748) appeared to have some levels of moderate resistance. However, the most promising resistance segregated in three $S$. habrochaites accessions (LA1731, LA2156, and LA2167). Resistant plants from these three $S$. habrochaites accessions were saved for selection. A secondary screening was carried out with progenies generated from the selected plants. These tests showed the segregation of broad-spectrum resistance from the selected S. habrochaites plants against PepMV, especially in LA1731. The segregated LA1731 plants were resistant to not only the U.S. type isolate but also the European type isolate.
\end{abstract}

Additional keyword: Potexvirus

Pepino mosaic virus (PepMV) is a member of the genus Potexvirus. The virus was first described on pepino (Solanum muricatum Aiton) in Peru in 1980 (5). The disease, however, was not observed on tomato (S. lycopersicum L.) until 1999 (20). In just a few years since the first observation on tomato, the disease has now been reported in Europe, North America, South America, and Asia (1,2,4,6,8,10$12,15,18,21,22)$. The seedborne nature of PepMV on tomato may have contributed to its rapid spread in greenhouse tomato around the world $(9,16)$. PepMV easily can be transmitted mechanically to tomato seedlings from a contaminated seed source and, thus, infected seed is considered a potential source of initial virus inoculum. The secondary transmission of PepMV is likely through contaminated hands or tools used in greenhouse tomato production.

Corresponding author: K. S. Ling

E-mail: kai.ling@ars.usda.gov

The use of trade, firm, or corporation names in this article does not imply the endorsement or approval by the United States Department of AgricultureAgricultural Research Service of any product to the exclusion of others that may be suitable.

Accepted for publication 16 January 2007.

doi:10.1094/PDIS-91-6-0749

This article is in the public domain and not copyrightable. It may be freely reprinted with customary crediting of the source. The American Phytopathological Society, 2007.
Several Solanum weed species (S. nigrum, S. aethiopicum, S. dulcamara, and S. luteum) were identified as hosts for PepMV (7). It is possible that these Solanum weeds common to the tomato ecosystem also play a role in the epidemiology of this disease.

At least 10 PepMV isolates have been completely sequenced to date $(1,2,8,10$, 11,13). Interestingly, genome sequences among European tomato isolates share high nucleotide sequence identity (99 to 100\%) (21). For example, the Spanish PepMV isolates are similar in genome sequences, even though the symptoms they induced are variable $(13,17)$. On the other hand, US1 and US2 isolates of PepMV are more diverse in genome sequences (11). US1 and US2 share $86 \%$ nucleotide sequence identity with each other and only 79 to $82 \%$ with the European tomato isolates. We recently characterized two virus variants (Ch1 and $\mathrm{Ch} 2$ ) obtained from an imported commercial tomato seed sample, originally produced in Chile (8). Ch1 was shown to be most closely related to the US1 isolate (with $99 \%$ sequence identity between the two) and Ch2 most closely related to the US2 isolate (with $91 \%$ sequence identity).

There are only limited options to combat this highly contagious disease. The current disease management strategy to limit PepMV transmission in greenhouse tomato production is by cultural practices. These approaches include the use of certified PepMV-free tomato seed, roguing of symptomatic seedlings, and the sanitiza- tion of hands and tools between plants. Because these cultural practices are not always effective, the use of resistant cultivars is the most desirable approach. Unfortunately, current tomato cultivars have no resistance to PepMV infection. There has been little published information on resistance to PepMV. Pico et al. (14) indicated that partial resistance to Spanish isolates existed in S. chilense accession LA1963 and S. peruvianum accessions PI 143679 and LA1708. Recently, Soler-Aleixandre et al. (19) reported partial resistance to a Spanish isolate of PepMV (European strain) in several $S$. chilense accessions. Little is known about the total number and type of accessions that have been tested and of the importance of strain effects on resistance. The objective of the present study was to evaluate a tomato germplasm core collection to genetically diverged isolates of PepMV for resistance.

\section{MATERIALS AND METHODS}

Tomato germplasm accessions. In all, 109 accessions belonging to five different species of Solanum were used (Table 1). Numbers of accessions tested were $23 \mathrm{~S}$. lycopersicum, $33 \mathrm{~S}$. peruvianum, $18 \mathrm{~S}$. chilense, and 27 S. habrochaites. Seed for these four species were obtained from the Tomato Genetics Resource Center (TGRC) at the University of California, Davis. Seed for eight $S$. pimpinellifolium accessions were produced in-house. Together, these accessions make up a core collection from the TGRC. At least 18 seeds per accession were germinated in Metro-Mix 360 soilless plant growth media (Sun Gro Horticulture, Bellevue, WA) in individual pots. Seedlings were germinated in an insectfree containment greenhouse with a temperature range of 18 to $30^{\circ} \mathrm{C}$ and natural lighting period of 12 to $14 \mathrm{~h}$. Depending on the germination rate, not all accessions reached the goal of 18 plants per accession. Plants were fertilized weekly with liquid fertilizer (20-20-20) to promote growth and viral symptom expression.

Virus sources and mechanical inoculation. An earlier study from our lab (8) showed that a PepMV culture generated from an imported commercial tomato seed sample contained two genetic variants (Ch1 and Ch2). The pairwise comparison of PepMV Ch1 and Ch2 genomes showed only $78 \%$ nucleotide sequence identity. They also shared only 78 to $86 \%$ nucleotide identity to several European type isolates. However, the highest nucleotide 
sequence identity was between $\mathrm{Ch} 1$ and US1 (99\%), or Ch2 and US2 (91\%) (8). Mixed infection of two genetic variants in a sample also was reported in the study of US1 and US2 strains (11). Because the original sample for US1 and US2 was limited and the live virus cultures were not available (11), we chose to use Ch1 and $\mathrm{Ch} 2$ isolates in this experiment to represent US1 and US2 isolates, respectively. The virus culture with a mixture of PepMV Ch1 and $\mathrm{Ch} 2$ was maintained on Nicotiana benthamiana. In addition, one new isolate originally collected from Texas (TX1), with a nucleotide sequence that is very similar to the European isolates ( $>98 \%$ in the coat protein gene) (K. S. Ling, unpublished data), was used in this study as a PepMV European isolate. Virus inoculum was prepared $(1: 5$, wt/vol) by macerating virusinfected leaf tissues in $0.01 \mathrm{M}$ phosphate saline buffer, $\mathrm{pH}$ 7.4. Tomato seedlings at the two- to three-leaf stage were dusted lightly with a layer of Carborundum. Mechanical inoculation was performed with a gentle rubbing on the Carborundumcovered leaves with a cotton swab soaked in the virus preparation. To ensure the maintenance of virus infectivity, three susceptible tomato plants (cv. Horizon) and three $N$. benthamiana plants were inoculated with the same virus preparation at the beginning and end of each inoculation process.

Primary screening of a tomato germplasm core collection. Inoculated plants were inspected weekly and the final reading was carried out 30 days post inoculation (DPI). Disease severity was rated on a 1-to-9 scale, where $1=$ no visible symptoms; 2 = older leaves showing mild mosaic, plant recovered in the apical leaves; 3 $=$ mild mosaic and mottling on leaves; $4=$ mosaic and yellow patches on leaves; 5 = severe yellow mosaic and mottling on leaves; $6=$ severe mottling and leaf blistering; 7 = plant stunting, leaf distortion, necrotic lesions on stems; $8=$ extensive necrotic lesions, flowers abort, mosaic symptoms on fruit; and $9=$ plant death. A disease severity index (DSI) was calculated with the mean disease ratings of all test plants in a given accession.

Serology. Enzyme-linked immunosorbent assay (ELISA) was conducted to ensure that the symptoms expressed on the test plants resulted from PepMV infection and to evaluate the level of virus accumulation in each plant. The PepMV antibody and its enzyme conjugate were supplied by Agdia (Elkhart, IN). Doubleantibody sandwich ELISA was conducted according to the manufacturer's instructions. Samples were prepared 1:20 (wt/vol) in tissue extraction buffer (BioReba, Switzerland). Absorbance values at $405 \mathrm{~nm}$ were measured with SpectraMax Plus384 (Molecular Devices, Sunnyvale, CA). Noninoculated and virus-infected cv. Horizon samples were included in each ELISA plate to serve as the negative

Table 1. List of the Solanum accessions used in the primary screening for resistance to Pepino mosaic virus (Ch1 and $\mathrm{Ch} 2$ isolates)

\begin{tabular}{|c|c|c|c|c|}
\hline Solanum lycopersicum & S. pimpinellifolium & S. peruvianum & S. chilense & S. habrochaites \\
\hline LA113 & LA1582 & LA107 & LA1932 & LA361 \\
\hline LA126 & Hirsute & LA153 & LA1938 & LA407 \\
\hline LA134c & $\mathrm{L} 10 / 3$ & LA441 & LA1959 & LA1223 \\
\hline LA146 & LA0121 & LA444 & LA1960 & LA1266 \\
\hline LA147 & LA0373 & LA453 & LA1963 & LA1347 \\
\hline LA172 & LA1690 & LA455 & LA1965 & LA1353 \\
\hline LA358 & PI 211840 & LA1032 & LA1969 & LA1361 \\
\hline LA404 & PI 212408 & LA1292 & LA1971 & LA1363 \\
\hline LA409 & & LA1305 & LA1972 & LA1560 \\
\hline LA466 & & LA1331 & LA2748 & LA1624 \\
\hline LA468 & & LA1358 & LA2755 & LA1691 \\
\hline LA473 & & LA1364 & LA2759 & LA1718 \\
\hline LA477 & & LA1379 & LA2767 & LA1721 \\
\hline LA1021 & & LA1395 & LA2773 & LA1731 \\
\hline LA1162 & & LA1474 & LA2778 & LA1777 \\
\hline LA1251 & & LA1626 & LA2879 & LA1918 \\
\hline LA2283 & & LA1910 & LA2884 & LA1928 \\
\hline LA2285 & & LA1929 & LA2931 & LA2098 \\
\hline LA2304 & & LA1937 & & LA2107 \\
\hline LA2307 & & LA1945 & & LA2109 \\
\hline EC 104395 & & LA1951 & & LA2119 \\
\hline PI 127821 & & LA1984 & & LA2155 \\
\hline \multirow[t]{11}{*}{ cv. Horizon } & & LA2151 & & LA2156 \\
\hline & & LA2157 & & LA2167 \\
\hline & & LA2163 & & LA2204 \\
\hline & & LA2185 & & LA2329 \\
\hline & & LA2561 & & \\
\hline & & LA2732 & & \\
\hline & & LA2744 & & \\
\hline & & LA2964 & & \\
\hline & & LA2981B & & \\
\hline & & LA3219 & & \\
\hline & & LA3797 & & \\
\hline
\end{tabular}

and positive controls, respectively. Mean absorbance and the standard deviation were calculated for each accession to estimate virus accumulation (3). The absorbance index $(\mathrm{ABI})$ was calculated using the ratio of the mean ELISA absorbance of each accession against that of the infected Horizon samples tested on the same microtiter plate.

Defining the level of resistance. Test plants expressing no symptoms (DSI rating of 1) and with no detectable level of virus accumulation in ELISA (ABI < 0.09) was considered to be highly resistant. Plants with a DSI rating of 2 and a significant reduction in absorbance values relative to that of the susceptible control (cv. Horizon) $(0.10<\mathrm{ABI}<0.19)$ were considered to be resistant. Test plants with a DSI rating of 3 and with a reduction in the ELISA absorbance $(0.20<\mathrm{ABI}<0.79)$ was considered to have moderate resistance. Tested plants with DSI ratings of 4 to 9 with no major reduction in virus accumulation $(0.8$ $<\mathrm{ABI}<1.0$ ) were considered to be susceptible. Plants with no symptoms (DSI rating of 1) and low or no detectable levels of PepMV in ELISA (ABI < 0.19) were saved for seed production and for further analyses of progenies.

Secondary screening of seedlings generated from single plant selection. The best-performing plants were saved for seed increase and additional tests for resistance. Three plants each from $S$. habrochaites LA1731 and LA2167 and a single plant in LA 2156 were selected for seed production. Because $S$. habrochaites is selfincompatible, fruit were produced through sibling pollination among plants in the same accession (LA1731 and LA2167) or between accessions (LA $2156 \times$ LA2167) when only one single resistant plant in LA 2156 was available. The secondary screening was conducted with progenies generated from these putative resistant plants, designated as LA1731-sib, LA2156 $\times$ LA2167, and LA2167-sib, respectively, with two different PepMV inoculum sources (a mixture of PepMV Ch1 and Ch2, and TX1).

\section{RESULTS}

Primary screening of tomato germplasm accessions with a mixture of PepMV Ch1 and Ch2. At 7 DPI, all 18 inoculated plants in the susceptible controls in tomato cv. Horizon and N. benthamiana began to show yellow mosaic symptoms on the inoculated leaves, indicating a high infectivity of the inoculum used and the uniformity of mechanical inoculation. Systemic infection was more pronounced at 14 DPI, with typical PepMV symptoms expressed on upper noninoculated leaves with mosaic, yellow patches, blisters, and leaf distortion. At 30 DPI, all inoculated control tomato plants developed severe disease symptoms (DSI $=5$ to 6 ) and possessed high absorbance values when 
evaluated by ELISA (optical density at 405 $\left.\mathrm{nm}\left[\mathrm{OD}_{405 \mathrm{~nm}}\right]=2.388\right)$. pimpinellifolium accessions tested were susceptible to PepMV. These accessions showed severe disease symptoms from virus infection, with DSI ranging from 4.2 to 6.0 for $S$. lycopersicum and 4.0 to 6.0 for $S$. pimpinellifolium accessions. When tested with ELISA, all $S$. lycopersicum plants had high levels of virus accumulation similar to that of the inoculated positive control cv. Horizon.

On the other hand, plants in 33 S. peruvianum accessions showed greater variations in responses to PepMV infection. Almost all accessions were susceptible to PepMV, with DSI ranging from 4.0 to 5.0. However, accession LA107 had a DSI of 3.3 (ABI of 0.71) and LA1305 had a DSI of 3.5 (ABI of 0.53 ). These two accessions were considered to be moderately resistant to PepMV (Table 2). less susceptible to PepMV, with DSI lower than 4.0 but higher than 3.0. The most promising accessions were LA1971 and LA2748, with DSIs of 3.0 and an ABI of 0.59 and 0.46 , respectively (Table 2). These accessions were regarded as moderately resistant to PepMV. All other $S$. chilense accessions, including LA1963, that previously had been shown by others (14) to have a partial resistance to Spanish
All $21 S$. lycopersicum and eight $S$.

Overall, 18 S. chilense accessions were

isolates of PepMV (European tomato strain), were considered to be susceptible to PepMV Ch1 and Ch2 infection.

The most interesting of the five Solanum spp. tested was $S$. habrochaites. Although 24 of the $27 S$. habrochaites accessions tested were susceptible to PepMV, 3 accessions (LA 1731, LA 2156, and LA 2167) exhibited a lower disease severity index $($ DSI $=3$ to 4$)$ and ELISA absorbance index $(\mathrm{ABI}=0.37$ to 0.78$)$ (Table 2$)$. Importantly, three plants in LA 1731, one in LA 2156, and three in LA 2167 remained symptomless, with low ELISA absorbance levels (ranging between 0.172 and 0.966), compared with a much higher ELISA reading $\left(\mathrm{OD}_{405 \mathrm{~nm}}=2.388\right)$ in the infected positive control. These seven selections were saved for seed production and further evaluation of resistance. Numerous seed were extracted from fruit generated by sibling pollination of the selected resistant plants in LA1731 and LA2167. Because only one single plant was saved in LA2156, hybrid seed was developed with cross pollination of the selected resistant plants between LA2156 and LA2167.

Secondary screening of the selected plants against PepMV. Two independent experiments were conducted. The first experiment was to confirm the resistance potential of progeny plants generated from three selected $S$. habrochaites accessions against the homologous isolates (a culture

Table 2. Selected Solanum accessions with potential resistance to Pepino mosaic virus (PepMV; Ch1 and $\mathrm{Ch} 2$ isolates) infection in the primary screening

\begin{tabular}{llccc}
\hline Accession & \multicolumn{1}{c}{ Genotype } & $\boldsymbol{n}^{\mathbf{a}}$ & ABI $^{\mathbf{b}}$ & DSI (range) $^{\mathbf{c}}$ \\
\hline LA107 & Solanum peruvianum & 17 & 0.71 & $3.3(3-5)$ \\
LA1305 & S. peruvianum & 18 & 0.53 & $3.5(3-5)$ \\
LA1971 & S. chilense & 11 & 0.59 & $3.0(3-3)$ \\
LA2748 & S. chilense & 4 & 0.46 & $3.0(3-3)$ \\
LA1731 & S. habrochaites & 8 & 0.68 & $3.5(3-4)$ \\
LA2156 & S. habrochaites & 4 & 0.37 & $3.3(3-4)$ \\
LA2167 & S. habrochaites & 11 & 0.78 & $3.4(3-4)$ \\
cv. Horizon & S. lycopersicum & 14 & 1.00 & $6.0(6-6)$ \\
\hline
\end{tabular}

a Number of plants tested.

${ }^{b}$ Absorbance index (ABI) was calculated using the ratio of the mean enzyme-linked immunosorbent assay absorbance of each accession against that of the PepMV-infected Horizon samples (i.e., positive control).

${ }^{c}$ Disease severity index (DSI) was the mean disease rating of all plants tested in a given accession. Disease severity was rated on a 1 -to- 9 scale, where $1=$ no visible symptoms; $2=$ older leaves showing mild mosaic, plant recovered in the apical leaves; $3=$ mild mosaic and mottling on leaves; $4=$ mosaic and yellow patches on leaves; $5=$ severe yellow mosaic and mottling on leaves; $6=$ severe mottling and leaf blistering; $7=$ plant stunting, leaf distortion, necrotic lesions on stems; $8=$ extensive necrotic lesions, flowers abort, mosaic symptoms on fruit; and $9=$ plant death. with the mixture of PepMV Ch1 and Ch2). Between 24 and 35 progeny seedlings from each accession were used. Only 2 of 90 total progeny plants screened from the three accessions expressed PepMV symptoms (Table 3). However, ELISA showed that many of the symptomless plants actually were infected. In the LA1731 progeny (LA 1731-sib), 9 of 35 had either a nondetectable or very low virus titer $\left(\mathrm{OD}_{405 \mathrm{~nm}}\right.$ $<0.19$ ), while all the plants in progenies of LA2156 × LA2167 and LA2167-sib contained mid to high levels of PepMV $\left(\mathrm{OD}_{405 \mathrm{~nm}}=0.200\right.$ to 2.00 ; Table 3$)$.

A second experiment was performed to determine whether the resistance in the selected plants also extended to a heterologous isolate, PepMV TX1. To our surprise, a large number of plants from the three selected accessions (19 of 28) had no symptom expression, although the control cv. Horizon was severely infected (Table 4). The best resistance to PepMV TX1 was also seen in LA1731-sib. A total of 6 of 10 plants tested had nondetectable levels of PepMV by ELISA. These plants were saved again for another round of selection.

\section{DISCUSSION}

Three sources of resistance to PepMV were identified in S. habrochaites accessions (LA1731, LA2156, and LA2167). Among them, LA1731-sib resulted in the highest level of resistance to PepMV infection against two inoculum sources consisting of genetically diverged isolates of PepMV (a mixture of Ch1 and Ch2, and TX1). Previously, other reports had identified partial resistance to PepMV European tomato isolates in S. chilense (LA470 and LA1963) and S. peruvianum (LA1708 and PI 143679) $(14,19)$. Among these four accessions, only LA1963 was included in our primary screening. Although we did not test LA1963 with the original Spanish isolate of PepMV (14), this accession in our tests was shown to be susceptible to the infection by a mixture of PepMV Ch1 and $\mathrm{Ch} 2$. This apparent difference in the resistance response to two genetic diverged strains of PepMV suggests that LA1963 may possess a strain-specific resistance to PepMV. Thus, the identification of resistance to several genetically diverged isolates of PepMV in the progenies of a single

Table 3. Secondary screening for resistance to Pepino mosaic virus (Ch1 and $\mathrm{Ch} 2$ isolates) with progeny generated from plant selections of Solanum habrochaites accessions

\begin{tabular}{|c|c|c|c|c|c|c|c|c|}
\hline \multirow[b]{2}{*}{ Accession-progeny } & \multirow[b]{2}{*}{$n^{\mathbf{c}}$} & \multicolumn{2}{|c|}{ Symptom $^{\mathrm{a}}$} & \multicolumn{5}{|c|}{ Enzyme-linked immunosorbent assay absorbance level ${ }^{b}$} \\
\hline & & Without & With & - & + & ++ & +++ & ++++ \\
\hline LA1731-sib & 35 & 35 & 0 & 5 & 4 & 17 & 4 & 5 \\
\hline LA2156 × LA2167 & 24 & 23 & 1 & 0 & 0 & 3 & 9 & 12 \\
\hline LA2167-sib & 31 & 30 & 1 & 0 & 0 & 3 & 17 & 11 \\
\hline cv. Horizon & 12 & 0 & 12 & 0 & 0 & 0 & 4 & 8 \\
\hline
\end{tabular}

${ }^{\mathrm{a}}$ Without and With $=$ number of plants without and with symptoms, respectively.

${ }^{\mathrm{b}}$ Designation of absorbance values at an optical density of $405 \mathrm{~nm}:-=<0.09,+=0.10$ to $0.19,++=>0.20$ to $0.99,+++=1.00$ to 1.99 , and $++++=>2.00$.

c Number of plants tested. 
Table 4. Secondary screening for resistance to Pepino mosaic virus TX1 with progeny plants generated from plant selections of Solanum habrochaites accessions

\begin{tabular}{|c|c|c|c|c|c|c|c|c|}
\hline \multirow[b]{2}{*}{ Accession-progeny } & \multirow[b]{2}{*}{$n^{\mathrm{c}}$} & \multicolumn{2}{|c|}{ Symptoma } & \multicolumn{5}{|c|}{ Enzyme-linked immunosorbent assay absorbance level ${ }^{b}$} \\
\hline & & Without & With & - & + & ++ & +++ & ++++ \\
\hline LA1731-sib & 10 & 7 & 3 & 6 & 0 & 0 & 4 & 0 \\
\hline LA2156 × LA2167 & 11 & 8 & 3 & 1 & 2 & 2 & 6 & 0 \\
\hline LA2167-sib & 7 & 4 & 3 & 0 & 1 & 1 & 5 & 0 \\
\hline cv. Horizon & 12 & 0 & 12 & 0 & 0 & 0 & 11 & 1 \\
\hline
\end{tabular}

a Without and With = number of plants without and with symptoms, respectively.

$\mathrm{b}$ Designation of absorbance values at an optical density of $405 \mathrm{~nm}:-=<0.09,+=0.10$ to $0.19,++=>0.20$ to $0.99,+++=1.00$ to 1.99 , and $++++=>2.00$.

c Number of plants tested.

accession (LA 1731-sib) from this study was significant.

Similar to the situation with a mixed infection of different genetic variants of PepMV in a field-collected sample (11), two genetic variants (Ch1 and Ch2) were identified only after genome sequencing of a field isolate generated from a commercial tomato seed sample (8). In an effort to select for a more durable level of resistance, we used a virus culture that contained a mixture of both genetic variants (Ch1 and Ch2) in the primary screening. This added level of selection pressure appears to have been effective, because the progeny seedlings generated from the three selected accessions (LA1731, LA2156, and LA2167) were not only resistant against the homologous isolates (PepMV Ch1 and Ch2) but also against the heterologous isolate (PepMV TX1).

Three asymptomatic LA1731 plants with reduced virus titers were sibpollinated, which resulted in progeny that were entirely symptomless to the mixed infection of PepMV Ch1 and Ch2. In addition, a larger proportion (9 of 35) of progeny plants had very low or nondetectable levels of virus accumulation than did the original population ( 1 of 8 ), again suggesting genetic gain. However, levels of virus accumulation in the progeny plants derived from LA1731-sib varied greatly $\left(\mathrm{OD}_{405 \mathrm{~nm}}\right.$ ranging from 0.10 to 2.00 ) in the apparently asymptomatic test plants, suggesting that resistance to PepMV replication in LA1731-sib potentially is controlled by another gene or genes in addition to those required to suppress symptom expression. Plants that had no detectable virus are presently being sib-pollinated and progeny then will be inoculated in an attempt to obtain a pure population that breeds true for resistance to PepMV Ch1 and $\mathrm{Ch} 2$ isolates. If such a population is attained, similar breeding steps will be taken to generate resistance to the PepMV TX1 isolate. In fact, after inoculation with the PepMV TX1 isolate (European type), 6 of the 10 tested LA1731-sib progeny plants were asymptomatic and had no detectable levels of PepMV, suggesting that there are genes in the LA1731-sib population that might confer resistance to the PepMV European isolates as well.
From our results, it does not appear that LA2167 is a likely source of resistance because no virus-free plants were obtained for either isolate. Also, when LA2156 was crossed with LA2167 and screened with the PepMV Ch1 and $\mathrm{Ch} 2$ isolates, all progeny were found to have detectable levels of virus. However, one plant with no symptoms and no detectable level of the virus was attained after inoculation with the TX1 isolate. It may be possible that LA2156 has a gene or genes that provide resistance to European isolates and, thus, crosses will be made using this plant. Resistance genes from LA2156 could be different than those in LA1731 and may prove useful in the future, as more extensive testing is done with other virus isolates.

The results reported herein are encouraging because it appears, for the first time, that resistance to three genetic diverged isolates of PepMV (Ch1, Ch2, and TX1) may have been attained. Development of tomato cultivars with resistance to PepMV would reduce not only yield losses due to the disease but also the need for tight regulation of seed and transplants currently necessary in the greenhouse tomato industry.

\section{ACKNOWLEDGMENTS}

Funding was provided by the United States Department of Agriculture through the Tomato Germplasm Committee, and seed for the tomato core collection were kindly supplied by the Tomato Genetics Resource Center, University of California, Davis. We thank W. P. Wechter and C. S. Kousik for their critical reading to the manuscript; and E. Marom, A. Gilliard, N. Khalilian, and E. Walters for their technical assistance.

\section{LITERATURE CITED}

1. Aguilar, J. M., Hernandez-Gallardo, M. D., Cenis, J. L., Lacasa, A., and Aranda, M. A. 2002. Complete sequence of the Pepino mosaic virus RNA genome. Arch. Virol. 147:2009-2015.

2. Cotillon, A. C., Girard, M., and Ducouret, S. 2002. Complete nucleotide sequence of the genomic RNA of a French isolate of Pepino mosaic virus (PepMV). Arch. Virol. 147:22312238.

3. Ding, X. S., Shintaku, M. H., Arnold, S. A., and Nelson, R. S. 1995. Accumulation of mild and severe strains of Tobacco mosaic virus in minor veins of tobacco. Mol. Plant-Microbe Interact. 8:32-40.

4. French, C. J., Bouthillier, M., Bernardy, M., Ferguson, G., Sabourin, M., Johnson, R. C., Masters, C., Godkin, S., and Mumford, R.
2001. First report of Pepino mosaic virus in Canada and the United States. Plant Dis. 85:1121.

5. Jones, R. A. C., Koenig, R., and Lesemann, D. E. 1980. Pepino mosaic virus, a new potexvirus from pepino Solanum muricatum. Ann Appl. Biol. 94:61-68.

6. Jorda, C., Lazaro-Perez, A., MartinezCulebras, P. V., Abad, P., Lacasa, A., and Guerrero, M. M. 2001. First report of Pepino mosaic virus on tomato in Spain. Plant Dis. 85:1292.

7. Kazinczi, G., Takacs, A. P., Horvath, J., Gaborjanyi, R. and Beres, I. 2005. Susceptibility of some weed species to Pepino mosaic virus (PepMV). Commun. Agric. Appl. Biol. Sci. 70:489-491.

8. Ling, K. S. 2007. Molecular characterization of two Pepino mosaic virus variants from imported tomato seed reveals high levels of sequence identity between Chilean and US isolates. Virus Genes 34:1-8.

9. Ling, K. S., and Carpenter, L. 2005. Pepino mosaic virus, an emerging disease in greenhouse tomato production worldwide: is seed responsible? Acta Hortic. 695:43-50.

10. Lopez, C., Soler, S., and Nuez, F. 2005. Comparison of the complete sequences of three different isolates of Pepino mosaic virus: size variability of the TGBp3 protein between tomato and $L$. peruvianum isolates. Arch. Virol 150:619-627.

11. Maroon-Lango, C. J., Guaragna, M. A., Jordan, R. L., Hammond, J., Bandla, M., and Marquardt, S. K. 2005. Two unique US isolates of Pepino mosaic virus from a limited source of pooled tomato tissue are distinct from a third (European-like) US isolate. Arch. Virol. 150:1187-1201.

12. Mumford, R. A., and Metcalfe, E. J. 2001. The partial sequencing of the genomic RNA of a UK isolate of Pepino mosaic virus and the comparison of the coat protein sequence with other isolates from Europe and Peru. Arch. Virol. 146:2455-2460.

13. Pagan, I., Cordoba-Selles, M. C., MartinezPriego, L., Fraile, A., Malpica, J. M., Jorda, C. and Garcia-Arenal, F. 2006. Genetic structure of the population of Pepino mosaic virus infecting tomato crops in Spain. Phytopathology 96:274-279.

14. Picó, B., J. Herraiz, J. J. Ruiz, and F. Nuez. 2002. Widening the genetic basis of virus resistance in tomato. Sci. Hortic. 94:73-89.

15. Roggero, P., Masenga, V., Lenzi, R., Coghe, F., Ena, S., and Winter, S. 2001. First report of Pepino mosaic virus in tomato in Italy. Plant Pathol. 50:798.

16. Salomone, A., and Roggero, P. 2002. Host range, seed transmission and detection by ELISA and lateral flow of an Italian isolate of Pepino mosaic virus. J. Plant Pathol. 84:65-68.

17. Soler, S., Prohens, J., Diez, M. J., and Nuez, F. 2002. Natural occurrence of Pepino mosaic virus in Lycopersicon species in Central and Southern Peru. J. Phytopathol. 150:49-53.

18. Soler-Aleixandre, S., Cebolla-Cornejo, J., and 
Nuez, F. 2005. Sources of resistance to Pepino mosaic virus (PepMV) in tomato. Rep. Tomato Genet. Coop. 55:43-45.

19. Soler-Aleixander, S., Lopez, C., Diez, M. J., Perez de Castro, A., and Nues, F. 2005. Association of Pepino mosaic virus with tomato collapse. J. Phytopathol. 153:464-469.
20. van der Vlugt, R. A. A., Stijger, C. C. M. M., Verhoeven, J. Th. J., and Lesemann, D. E. 2000. First report of Pepino mosaic virus on tomato. Plant Dis. 84:103.

21. Verhoeven, J. Th. J., van der Vlugt, R. A. A., and Roenhorst, J. W. 2003. High similarity between tomato isolates of Pepino mosaic virus suggests a common origin. Eur. J. Plant Pathol. 109:419-425

22. Zhang, Y., Shen, Z. J., Zhong, J., Lu, X. L., Cheng, G., and Li, R. D. 2003. Preliminary characterization of Pepino mosaic virus Shanghai isolate (PepMV-Sh) and its detection with ELISA. Acta Agric. Shanghai 19:90-92. 